\title{
Metatarsal Artery
}

National Cancer Institute

\section{Source}

National Cancer Institute. Metatarsal Artery. NCI Thesaurus. Code C33107.

Any of the four dorsal or four plantar arteries that arise from the dorsalis pedis artery

that extend over the metatarsal bones. 